\title{
Independent External Validation of a Score Predicting Survival After Radiotherapy for Bone Metastases and Expansion to Patients Treated With Single Fraction Radiotherapy
}

\author{
Carsten Nieder ${ }^{\mathrm{a}, \mathrm{b}, \mathrm{c}}$, Bard Mannsaker ${ }^{\mathrm{a}}$, Astrid Dalhauga, b
}

\begin{abstract}
Background: Recently a prognostic score that predicts 12-month survival in patients treated with fractionated radiotherapy for painful bone metastases has been developed. Fractionated radiotherapy might cause unnecessary burden for patients with limited survival, thus estimation of survival is clinically relevant. The purpose of the present study was independent external validation of the new score and, in addition, its application in patients who received single fraction irradiation, a convenient option currently endorsed in several guidelines.
\end{abstract}

Methods: We conducted a retrospective analysis of 270 patients, including $24 \%$ who had received single fraction irradiation. The threetiered score was assigned as described in the development study, and included age, performance status and primary tumor type. Additional prognostic factors not studied in the development cohort, such as the Glasgow prognostic score (GPS) and presence of liver metastases, were included in this validation study.

Results: The three-tiered score was valid in this independent cohort (12-month survival rates were $7 \%, 30 \%$ and $71 \%$, respectively, $\mathrm{P}=$ $0.0001)$. Its performance and validity were also confirmed in the single fraction radiotherapy group. Three additional prognostic factors were significant in the multivariate analysis and may therefore contribute to decision making.

Conclusions: Irrespective of fractionation, the score based on age, performance status and primary tumor type provides a readily available estimate of 12-month survival.

Keywords: Radiotherapy; Radiation oncology; Bone metastases;

Manuscript submitted December 5, 2019, accepted January 6, 2020

aDepartment of Oncology and Palliative Medicine, Nordland Hospital, 8092 Bodo, Norway

'Institute of Clinical Medicine, Faculty of Health Sciences, University of Tromso, 9038 Tromso, Norway

${ }^{\mathrm{c} C}$ Corresponding Author: Carsten Nieder, Department of Oncology and Palliative Medicine, Nordland Hospital, 8092 Bodo, Norway.

Email: carsten.nieder@nlsh.no
Fractionation regimen; Prognostic factors; Score

\section{Introduction}

Most radiotherapy centers worldwide are treating considerable numbers of patients with bone metastases from solid tumors [1-4]. Several prospective randomized trials have confirmed the high efficacy of radiation treatment in terms of pain relief [5-14]. Various palliative radiotherapy schedules have been studied, ranging from a single fraction of $8 \mathrm{~Gy}$, to $20 \mathrm{~Gy}$ in 5 fractions, $24 \mathrm{~Gy}$ in 6 fractions, $30 \mathrm{~Gy}$ in 10 fractions and even $40 \mathrm{~Gy}$ in 20 fractions. No clear dose-effect relationship has been seen in any of these trials. Subsequent meta-analyses have confirmed the equal effectiveness of a single dose schedule compared to more protracted regimens [15-17]. Several guidelines and consensus reports recommend a single fraction of $8 \mathrm{~Gy}$ as preferred radiotherapy schedule for patients with uncomplicated bone pain, that is, for bone lesions not causing neurological complaints and without a high risk of pathological fracture [18-21]. Among the randomized trials comparing single versus multiple fractions for painful bone metastases, retreatment rates were consistently higher after the single dose schedules. If patients with long predicted survival require treatment with a low risk of local failure, protracted regimens are commonly prescribed [22-24]. In order to avoid unnecessary overtreatment and assign the right patient to the right radiotherapy regimen, Rades et al have recently developed a prognostic model that predicts 12-month survival [25]. All patients had received fractionated radiotherapy for symptomatic (painful) bone metastases without spinal cord compression between 2009 and 2017, and had solid tumors. The purpose of the present study was independent external validation of the Rades et al score and, in addition, its application in patients who received single fraction irradiation, a convenient option currently endorsed in several guidelines.

\section{Materials and Methods}

This retrospective validation study utilized a previously es- 
tablished database (purpose: monitoring of quality of care) at the authors' institution in Bodo (academic teaching hospital in rural Norway) [26]. All patients were treated with linear accelerators between 2007 and 2014 after 2D or 3D treatment planning (no stereotactic radiotherapy). While single fraction irradiation was recommended for uncomplicated bone metastases, final decision-making was left to the discretion of the treating physician. In accordance with the Rades et al study, and to resemble its methods as closely as possible, patients with metastatic spinal cord compression were excluded, because separate prognostic models exist for this group [27-29]. Location of metastases included spine, pelvis, long bones, ribs, skull, etc. Patients who had experienced complications, such as pathological fractures, and were treated with surgery and postoperative radiotherapy were included. The latter group was not treated with single fraction irradiation.

Institutional Review Board approval was not required because an already approved database created for retrospective quality-of-care studies was analyzed. This study was conducted in compliance with the ethical standards of the responsible institution on human subjects as well as with the Helsinki Declaration.

Serum albumin and C-reactive protein (CRP) were part of routine blood chemistry assessment and used to assign the Glasgow prognostic score (GPS), in accordance with a previous study by our group, which suggested high clinical relevance for survival prediction [30]. GPS 0 describes a state of normal CRP and albumin; GPS 1 describes one abnormal result; GPS 2 describes increased CRP and low albumin. The hospital's electronic patient record system was used to collect all follow-up and baseline data including blood tests. The latter had to be no older than 2 weeks before the first fraction of radiotherapy.

The Rades et al score was assigned based on age, Karnofsky performance status (KPS) and primary tumor as described in literature [25]. Patients who were 60 years or younger received 5 points, whereas their older counterparts received 4 points. In case of KPS 80 - 100, 6 points were assigned (KPS $\leq 70: 2$ points). The different primary tumors were counted as follows: 6 points for breast and renal cell cancer, 5 points for prostate cancer, 3 points for lung and colorectal cancer and 2 points for other tumors.

Actuarial survival from the first day of radiotherapy was calculated with the Kaplan-Meier method and compared between subgroups with differing baseline characteristics with the log-rank test. In case of a new course of bone irradiation during follow-up, patients were censored at the date of treatment start of their new course. If the log-rank P-value was $\leq$ 0.05 , the corresponding baseline characteristic was included in the multivariate analysis of prognostic factors for survival, which consisted of Cox regression (forward conditional method). A P-value $\leq 0.05$ was considered statistically significant.

\section{Results}

We identified and included 270 patients from our database. Single fraction irradiation was administered to 64 patients $(24 \%)$, short course ( 4 - 6 fractions, e.g. 5 fractions of 4 Gy) to 71 patients $(26 \%)$ and long course (10 fractions of 3 Gy or higher biologically equivalent doses) to 135 patients $(50 \%)$. Commonly, only one target volume was treated (141 patients, $52 \%$; two target volumes at the same time: $36 \%$; more than two: $12 \%)$. Eleven patients $(4 \%)$ failed to complete treatment. Median age was 66.5 years (minimum 33, maximum 89 years). Fifty-nine patients $(22 \%)$ were 60 years or younger. Most patients were male (178, 66\%; female: $92,34 \%)$ and had KPS 80 - $100(191,71 \%$; KPS $\leq 70: 79,29 \%)$. Primary tumors were as follows: prostate $42 \%$, breast $17 \%$, lung $13 \%$, kidney $10 \%$, colorectal $3 \%$ and others $14 \%$. A favorable GPS score (0) was recorded in 112 patients (41\%), intermediate (1) in 110 patients (41\%) and poor (2) in 48 patients (18\%).

As shown in Figure 1, survival varied with fractionation. In the single fraction group, a median of 6.0 months was observed (short course: 9.7 months, long course: 26.6 months) (P $=0.0001)$. Comparable differences were seen for GPS $(1.8,9.8$ and 37.4 months, $\mathrm{P}=0.0001$ ), different primary tumors (longest survival in prostate, breast and kidney, $\mathrm{P}=0.0001)$, KPS $(\mathrm{P}=0.0001)$, presence of liver metastases $(\mathrm{P}=0.0001)$ and known disease progression outside of the irradiated bone target volumes $(\mathrm{P}=0.0001)$. In contrast, age as continuous variable was not significant in a univariate Cox analysis $(\mathrm{P}=0.07)$.

Regarding the Rades et al score, which was assigned based on age, KPS and primary tumor as described in literature [25], most patients belonged to the favorable group (15 - 17 points, $\mathrm{n}=143,53 \%)$, followed by the intermediate group (10 - 14 points, 97 patients, 36\%) and the unfavorable group (8 - 9 points, 30 patients, $11 \%$ ) (Table 1$)$. The median point sum was 15 (range 8 - 17). The survival curves are shown in Figure 2 (P $=0.0001)$. The rates of 12-month survival were $7 \%, 30 \%$ and $71 \%$, respectively. Figures 3-5 display survival stratified by fractionation regimen. The Rades et al score predicted survival in all three different fractionation groups $(\mathrm{P}=0.0001)$ for all three figures. Outcomes are summarized in Table 2.

The multivariate Cox regression model included the Rades et al score, GPS, fractionation, liver metastases and progressive disease outside of the irradiated bone target volumes. Besides fractionation $(\mathrm{P}=0.13)$, all other variables were associated with survival $(\mathrm{P}=0.005$ or better $)$. The hazard ratios were 1.9 for the presence of liver metastases, 1.8 for the presence of progressive disease outside of the irradiated bone target volumes, 1.6 for worse GPS and 0.3 for better Rades score.

\section{Discussion}

Rades et al have recently published their score predicting survival after fractionated radiotherapy for bone metastases [25]. Their study included approximately 400 patients. The fractionation regimen (short course with 5 - 6 fractions of $4 \mathrm{~Gy}$ vs. long course with 30 - 40 Gy in 10 - 20 fractions) plus 13 baseline factors were investigated for potential associations with survival. These factors included age ( $\leq 60$ vs. $61-70$ vs. $>70$ years), gender, KPS ( $\leq 70$ vs. $80-100$ ), primary tumor type (breast cancer vs. prostate cancer vs. lung cancer vs. kidney cancer vs. colorectal cancer vs. other tumors), interval between cancer diagnosis and irradiation of bone metastases $(\leq$ 

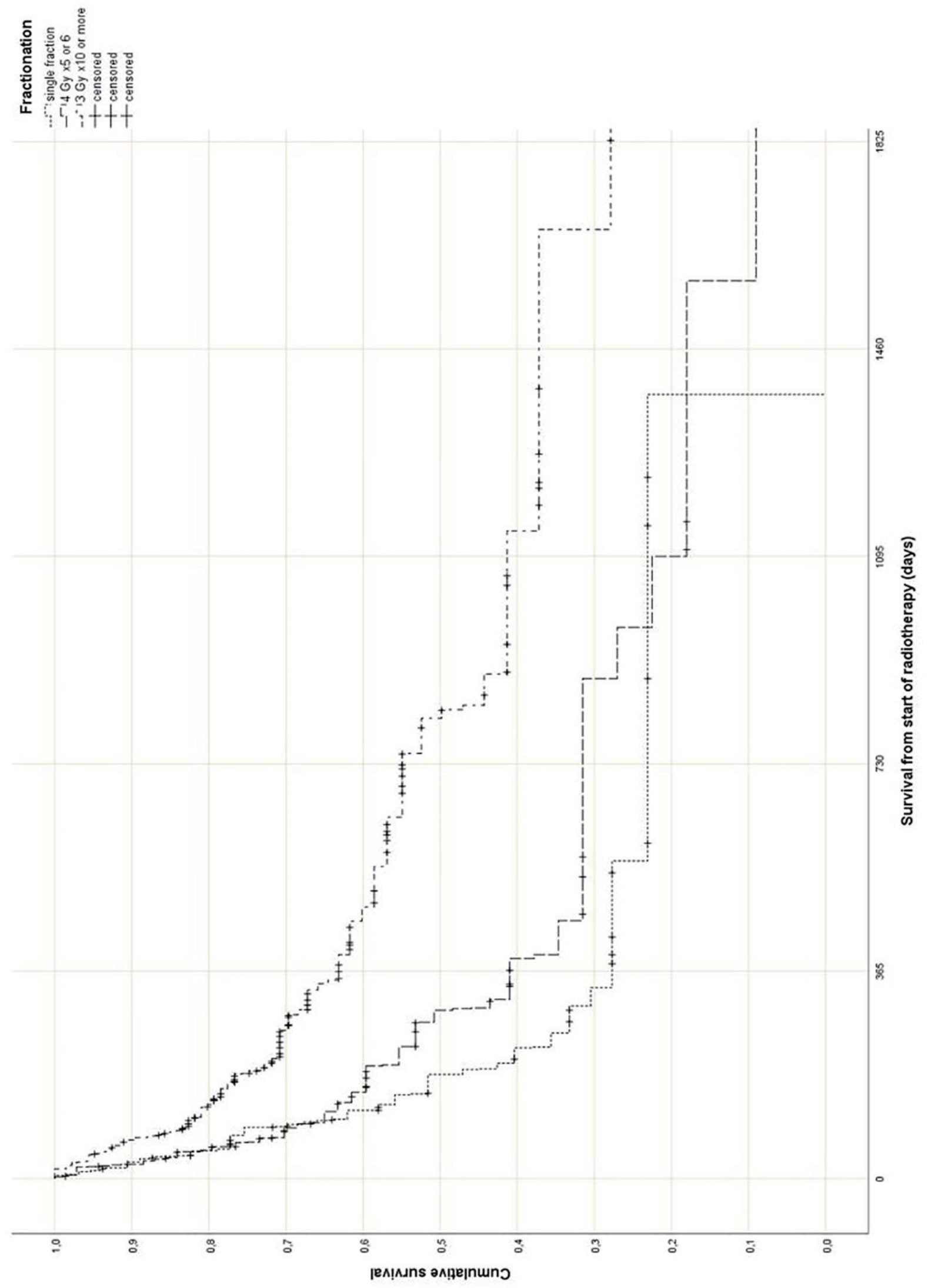

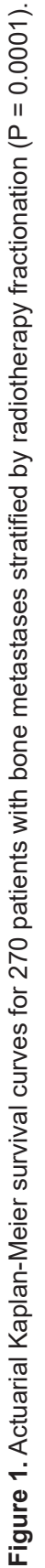


Table 1. Distribution of Score Parameters

\begin{tabular}{llll}
\hline Parameters & Favorable score & Intermediate score & Unfavorable score \\
\hline Median age, years & 67 & 65 & 69 \\
Age $\leq 60$ years, $\%$ & 22 & 26 & 10 \\
Karnofsky performance status $80-100, \%$ & 100 & 49 & 0 \\
Breast cancer, $\%$ & 26 & 10 & 0 \\
Renal cell cancer, $\%$ & 14 & 8 & 0 \\
Prostate cancer, $\%$ & 60 & 29 & 0 \\
Lung cancer, $\%$ & 0 & 22 & 47 \\
Colorectal cancer, $\%$ & 0 & 5 & 7 \\
Other cancer, $\%$ & 0 & 26 & 46 \\
Median point sum & 15 & 12 & 9 \\
\hline
\end{tabular}

8 vs. $\geq 9$ months), visceral metastases (no vs. yes), other (nonirradiated) bone metastases (no vs. yes), location of irradiated bone metastases (spinal site(s) only vs. extraspinal site(s) with or without spinal site(s)), number of irradiated sites (single vs. multiple), pathological fracture (no vs. yes), pre-radiotherapy surgery (no vs. yes), pre-radiotherapy administration of bisphosphonates/denosumab (no vs. yes) and pre-radiotherapy systemic anticancer treatment (no vs. yes). Of these factors, only KPS, primary tumor type and age were relevant to the survival score, and three different prognostic groups were constructed (Fig. 2, Table 1).

The purpose of the present study was independent external validation of the Rades et al score and, in addition, its application in patients who received single fraction irradiation, a convenient option currently endorsed in several guidelines [18-21]. The optimal utilization rate of single fraction radiotherapy is unknown and depends on institutional case mix. In the prospective randomized Dutch bone metastasis study (single fraction of 8 Gy vs. 24 Gy in 6 fractions), 28\% of the patients survived for more than 1 year $[10,14,31]$. In these 320 patients with better prognosis, responses were $87 \%$ after 8 Gy and $85 \%$ after 24 Gy $(\mathrm{P}=0.54)$. Duration of response and progression rates were similar. Regarding validation of the Rades et al score, we replicated their methods as closely as possible. In addition, potential prognostic factors that were not assessed by Rades et al were included (GPS, liver metastases and disease progression outside of the irradiated bone target volumes). As shown in Table 1, there was good agreement regarding 12-month survival rates between the development and validation studies. The score stratifies patients into three subsets with clearly distinct prognoses. Comparable to the Rades et al study, the impact of age was much smaller than that of KPS and primary tumor type.

The present multivariate analysis suggests that additional prognostic factors may be taken into consideration when making treatment decisions, e.g. GPS, liver metastases and disease progression outside of the irradiated bone target volumes. Figures 3-5 suggest that the physicians in our department prescribed the number of radiotherapy fractions according to the patients expected survival. However, the administration of higher doses of radiation was not associated with improved survival in the multivariate analysis. It is also evident from these figures that the Rades et al score can be applied in cohorts treated with single fraction radiotherapy. Importantly, survival of prognostically poor patients after single fraction radiotherapy was very short (median 1 month, 12-month rate $0 \%$ ), suggesting that many of these patients are unlikely to derive clinical benefit. Current strategies for patients with limited disease extent and long predicted survival include stereotactic and other advanced radiotherapy modalities [32]. It would be interesting to study the Rades et al score in patient cohorts managed with these approaches as well.

\section{Acknowledgments}

None to declare.

\section{Financial Disclosure}

No funding was received for this study.

\section{Conflict of Interest}

The authors declare that they have no competing interests.

\section{Informed Consent}

All patients provided informed consent before starting with their routine clinical treatment regimens that were evaluated in this study.

\section{Author Contributions}

$\mathrm{CN}$ analyzed and interpreted the patient data regarding the Rades et al score. All authors contributed in writing the manuscript. All authors read and approved the final manuscript. 

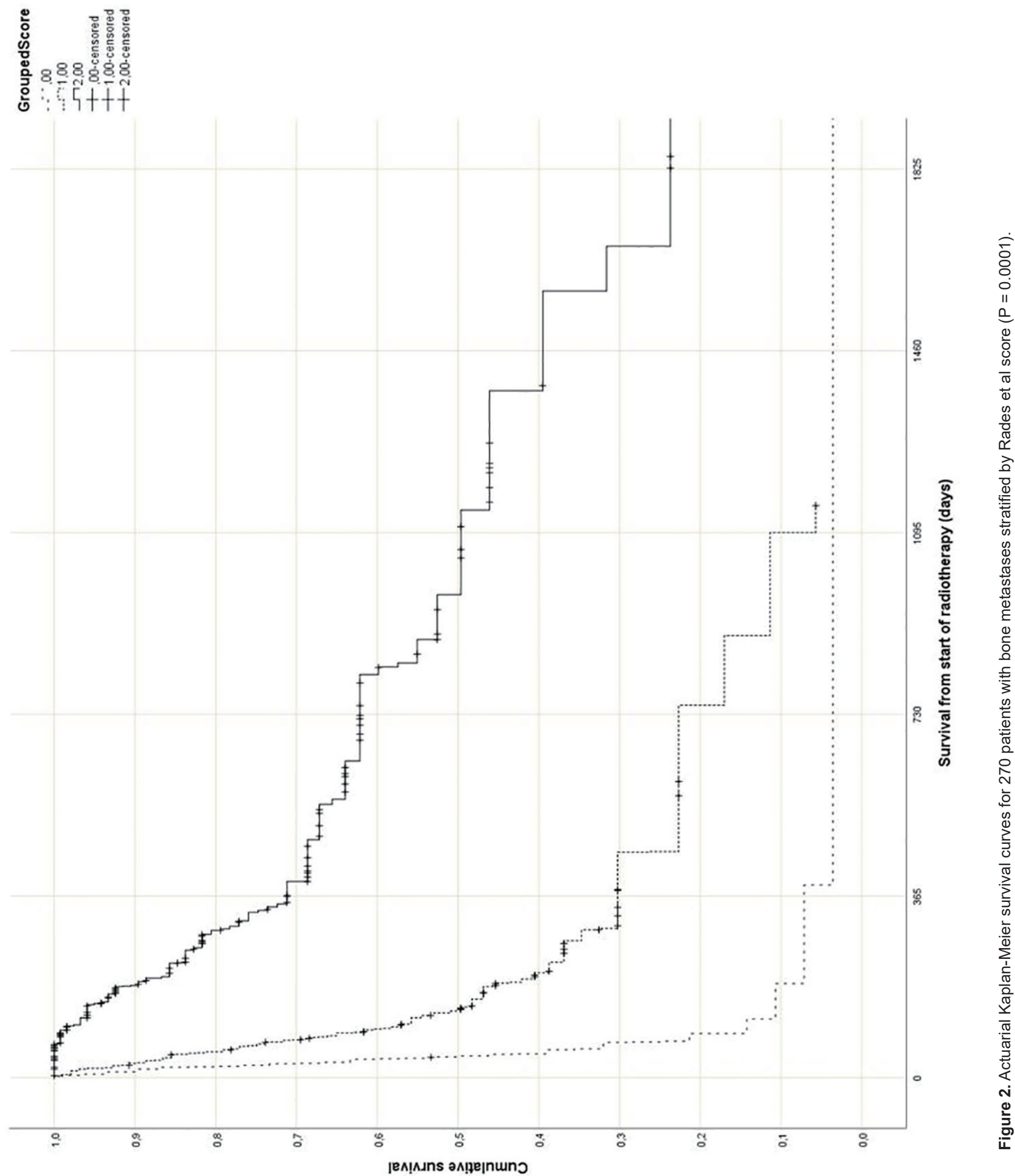

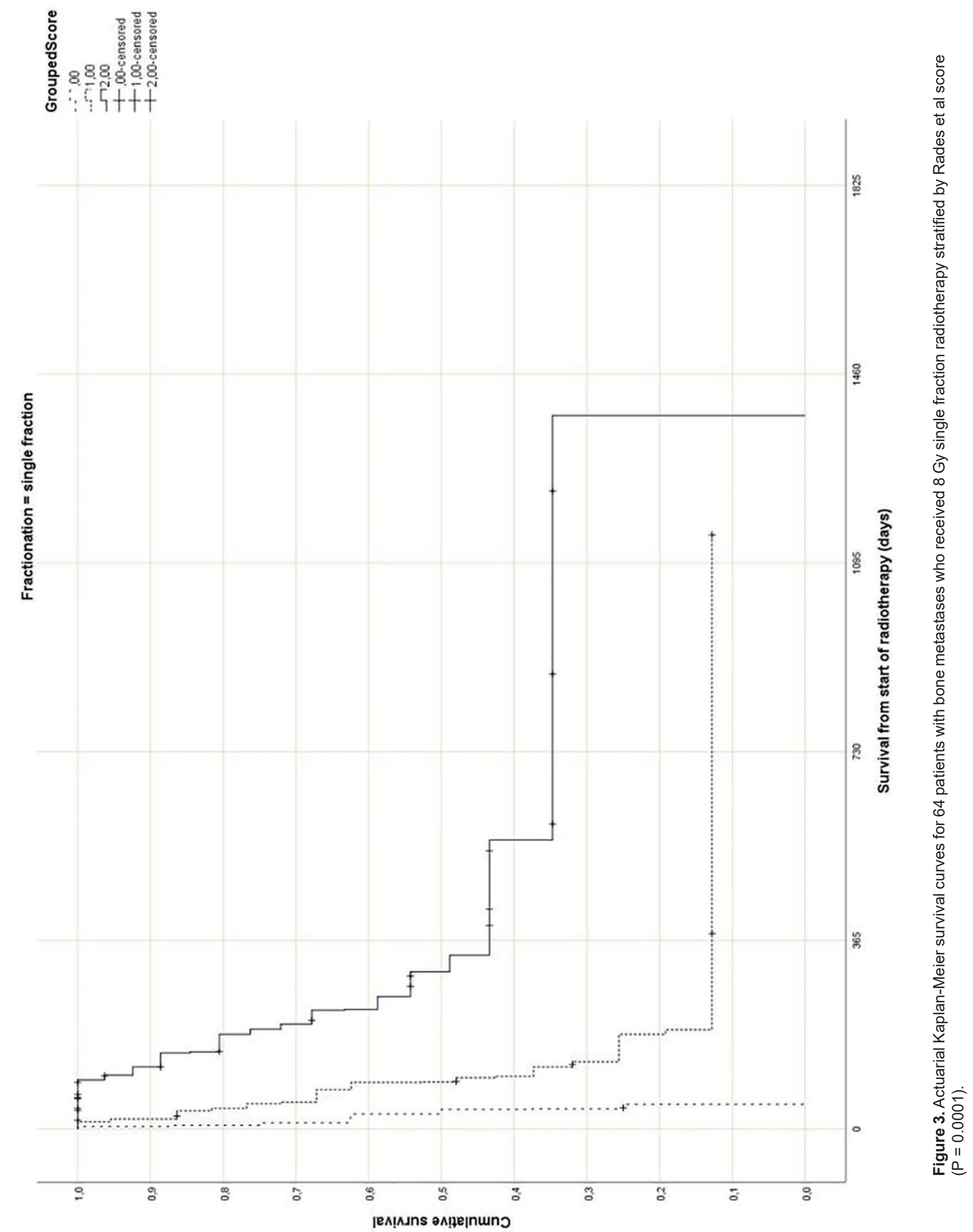


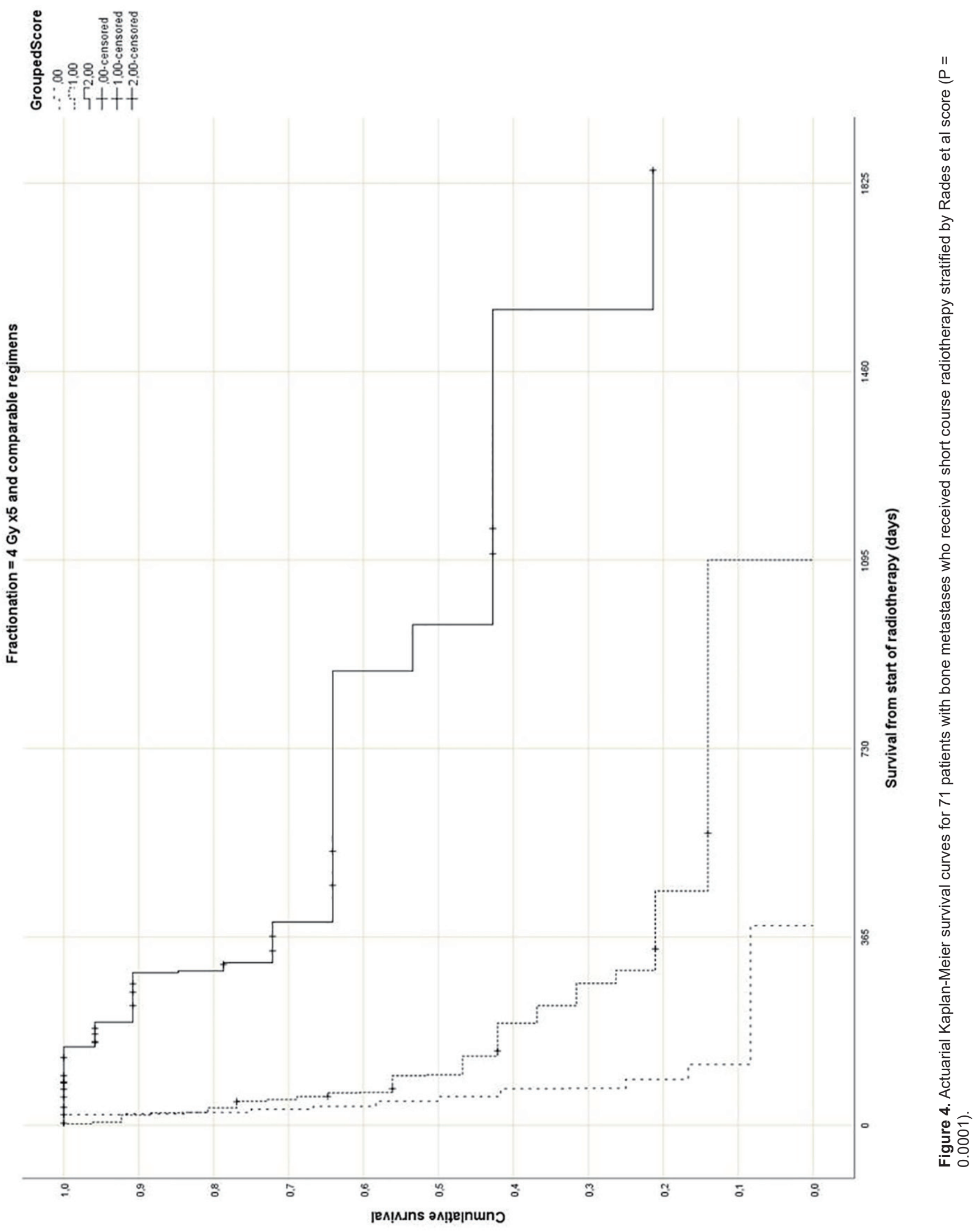




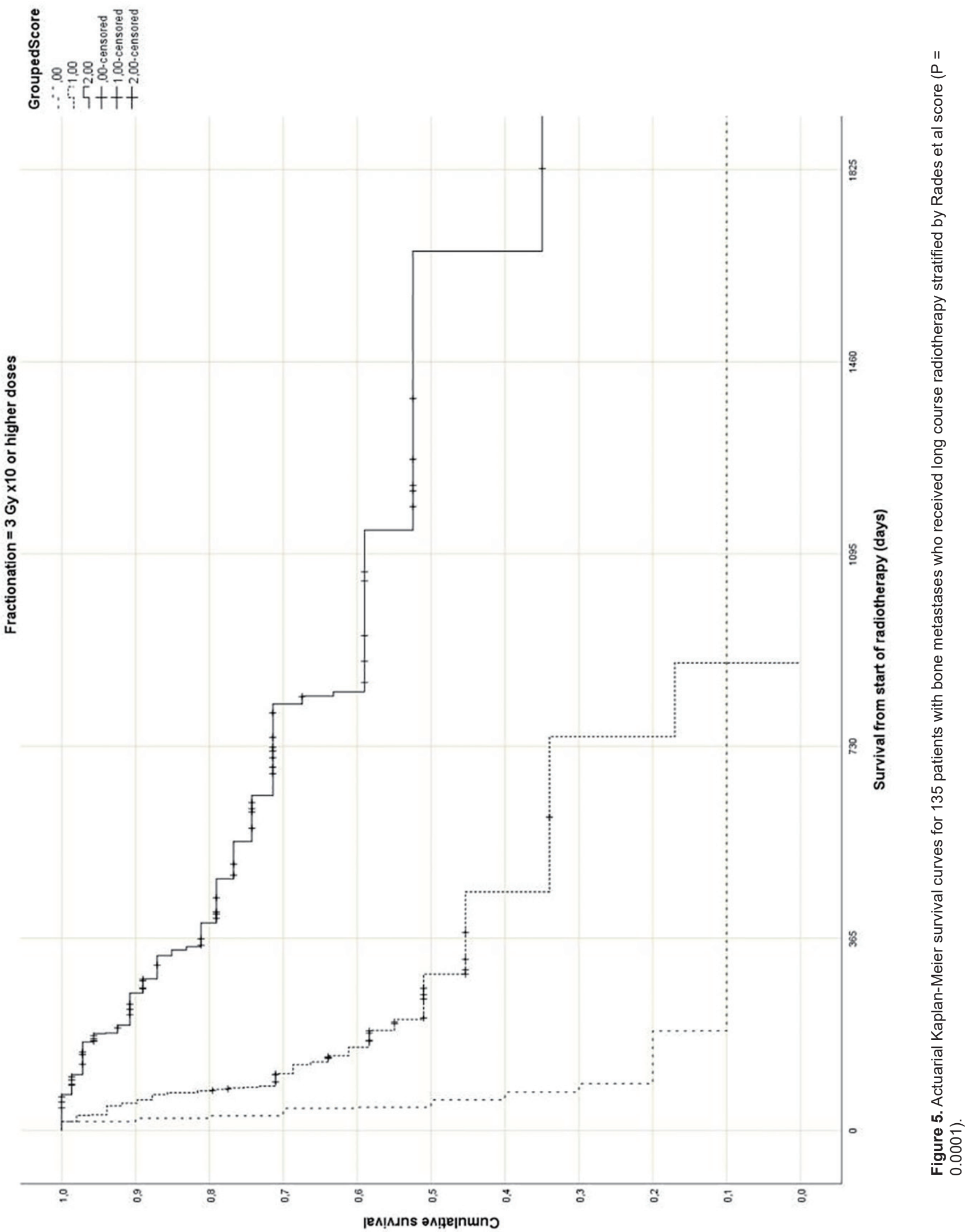


Table 2. Results Overview

\begin{tabular}{lll}
\hline Group & $\mathbf{1 2 - m o n t h ~ s u r v i v a l ~}$ & Median survival \\
\hline Rades et al favorable & $72 \%$ & 24 months \\
Rades et al intermediate & $38 \%$ & 8 months \\
Rades et al unfavorable & $9 \%$ & 3 months \\
Present study favorable & $71 \%$ & 31.8 months \\
Present study intermediate & $30 \%$ & 4.4 months \\
Present study unfavorable & $7 \%$ & 1.4 months \\
Present study 8 Gy favorable & $43 \%$ & 10.0 months \\
Present study 8 Gy intermediate & $13 \%$ & 3.0 months \\
Present study 8 Gy unfavorable & $0 \%$ & 1.0 month \\
Present study short course favorable & $72 \%$ & 31.8 months \\
Present study short course intermediate & $21 \%$ & 3.2 months \\
Present study short course unfavorable & $8 \%$ & 1.5 months \\
Present study long course favorable & $81 \%$ & 54.8 months \\
Present study long course intermediate & $45 \%$ & 9.7 months \\
Present study long course unfavorable & $10 \%$ & 1.4 months \\
\hline
\end{tabular}

\section{Data Availability}

Any inquiries regarding supporting data availability of this study should be directed to the corresponding author.

\section{References}

1. Falkmer U, Jarhult J, Wersall P, Cavallin-Stahl E. A systematic overview of radiation therapy effects in skeletal metastases. Acta Oncol. 2003;42(5-6):620-633.

2. Bedard G, Hoskin P, Chow E. Overall response rates to radiation therapy for patients with painful uncomplicated bone metastases undergoing initial treatment and retreatment. Radiother Oncol. 2014;112:125-127.

3. Gebhardt BJ, Rajagopalan MS, Gill BS, Heron DE, Rakfal SM, Flickinger JC, Beriwal S. Impact of dynamic changes to a bone metastases pathway in a large, integrated, National Cancer Institute-designated comprehensive cancer center network. Pract Radiat Oncol. 2015;5(6):398-405.

4. Nieder C, Dalhaug A, Haukland E, Mannsaker B, Pawinski A. Contemporary radiooncological management of bone metastases from breast cancer: factors associated with prescription of different fractionation regimens (short or long course) in a rural part of North Norway with long travel distance. Int J Circumpolar Health. 2017;76(1):1270080.

5. Hoskin PJ, Price P, Easton D, Regan J, Austin D, Palmer $\mathrm{S}$, Yarnold JR. A prospective randomised trial of 4 Gy or 8 Gy single doses in the treatment of metastatic bone pain. Radiother Oncol. 1992;23(2):74-78.

6. Niewald M, Tkocz HJ, Abel U, Scheib T, Walter K, Nieder C, Schnabel K, et al. Rapid course radiation therapy vs. more standard treatment: a randomized trial for bone me- tastases. Int J Radiat Oncol Biol Phys. 1996;36(5):10851089.

7. Gaze MN, Kelly CG, Kerr GR, Cull A, Cowie VJ, Gregor A, Howard GC, et al. Pain relief and quality of life following radiotherapy for bone metastases: a randomised trial of two fractionation schedules. Radiother Oncol. 1997;45(2):109-116.

8. Jeremic B, Shibamoto Y, Acimovic L, Milicic B, Milisavljevic S, Nikolic N, Aleksandrovic J, et al. A randomized trial of three single-dose radiation therapy regimens in the treatment of metastatic bone pain. Int J Radiat Oncol Biol Phys. 1998;42(1):161-167.

9. Nielsen OS, Bentzen SM, Sandberg E, Gadeberg CC, Timothy AR. Randomized trial of single dose versus fractionated palliative radiotherapy of bone metastases. Radiother Oncol. 1998;47(3):233-240.

10. Steenland E, Leer JW, van Houwelingen H, Post WJ, van den Hout WB, Kievit J, de Haes H, et al. The effect of a single fraction compared to multiple fractions on painful bone metastases: a global analysis of the Dutch Bone Metastasis Study. Radiother Oncol. 1999;52(2):101-109.

11. Hartsell WF, Scott CB, Bruner DW, Scarantino CW, Ivker RA, Roach M, 3rd, Suh JH, et al. Randomized trial of short- versus long-course radiotherapy for palliation of painful bone metastases. J Natl Cancer Inst. 2005;97(11):798-804.

12. Kaasa S, Brenne E, Lund JA, Fayers P, Falkmer U, Holmberg M, Lagerlund M, et al. Prospective randomised multicenter trial on single fraction radiotherapy ( 8 Gy x 1) versus multiple fractions (3 Gy x 10) in the treatment of painful bone metastases. Radiother Oncol. 2006;79(3):278-284.

13. Foro Arnalot P, Fontanals AV, Galceran JC, Lynd F, Latiesas XS, de Dios NR, Castillejo AR, et al. Randomized clinical trial with two palliative radiotherapy regimens 
in painful bone metastases: $30 \mathrm{~Gy}$ in 10 fractions compared with 8 Gy in single fraction. Radiother Oncol. 2008;89(2):150-155.

14. Spencer K, Velikova G, Henry A, Westhoff P, Hall PT, van der Linden YM. Net Pain Relief After Palliative Radiation Therapy for Painful Bone Metastases: A Useful Measure to Reflect Response Duration? A Further Analysis of the Dutch Bone Metastasis Study. Int J Radiat Oncol Biol Phys. 2019;105(3):559-566.

15. Chow E, Harris K, Fan G, Tsao M, Sze WM. Palliative radiotherapy trials for bone metastases: a systematic review. J Clin Oncol. 2007;25(11):1423-1436.

16. Chow E, Zeng L, Salvo N, Dennis K, Tsao M, Lutz S. Update on the systematic review of palliative radiotherapy trials for bone metastases. Clin Oncol (R Coll Radiol). 2012;24(2):112-124.

17. Chow R, Hoskin P, Schild SE, Raman S, Im J, Zhang D, Chan $\mathrm{S}$, et al. Single vs multiple fraction palliative radiation therapy for bone metastases: Cumulative meta-analysis. Radiother Oncol. 2019;141:56-61.

18. Lutz S, Berk L, Chang E, Chow E, Hahn C, Hoskin P, Howell D, et al. Palliative radiotherapy for bone metastases: an ASTRO evidence-based guideline. Int J Radiat Oncol Biol Phys. 2011;79(4):965-976.

19. Raman S, Chow R, Hoskin P, Chow E. How should radiation oncologists interpret the ASTRO evidence-based guideline and ASTRO Choosing Wisely campaign for the treatment of uncomplicated bone metastases? Pract Radiat Oncol. 2017;7(1):13-15.

20. Shibata H, Kato S, Sekine I, Abe K, Araki N, Iguchi H, Izumi T, et al. Diagnosis and treatment of bone metastasis: comprehensive guideline of the Japanese Society of Medical Oncology, Japanese Orthopedic Association, Japanese Urological Association, and Japanese Society for Radiation Oncology. ESMO Open. 2016;1(2):e000037.

21. Ganesh V, Chan S, Raman S, Chow R, Hoskin P, Lam $\mathrm{H}$, Wan BA, et al. A review of patterns of practice and clinical guidelines in the palliative radiation treatment of uncomplicated bone metastases. Radiother Oncol. 2017;124(1):38-44.

22. Fairchild A, Barnes E, Ghosh S, Ben-Josef E, Roos D, Hartsell W, Holt T, et al. International patterns of practice in palliative radiotherapy for painful bone metastases: evidence-based practice? Int J Radiat Oncol Biol Phys. 2009;75(5):1501-1510.
23. Nakamura N, Shikama N, Wada H, Harada H, Nozaki M, Nagakura H, Tago M, et al. Patterns of practice in palliative radiotherapy for painful bone metastases: a survey in Japan. Int J Radiat Oncol Biol Phys. 2012;83(1):e117120.

24. Nieder C, Pawinski A, Dalhaug A. Continuous controversy about radiation oncologists' choice of treatment regimens for bone metastases: should we blame doctors, cancer-related features, or design of previous clinical studies? Radiat Oncol. 2013;8:85.

25. Rades D, Haus R, Schild SE, Janssen S. Prognostic factors and a new scoring system for survival of patients irradiated for bone metastases. BMC Cancer. 2019;19(1):1156.

26. Nieder C, Haukland E, Mannsaker B, Norum J. Impact of intense systemic therapy and improved survival on the use of palliative radiotherapy in patients with bone metastases from prostate cancer. Oncol Lett. 2016;12(4):29302935.

27. Rades D, Stalpers LJ, Veninga T, Schulte R, Hoskin PJ, Obralic N, Bajrovic A, et al. Evaluation of five radiation schedules and prognostic factors for metastatic spinal cord compression. J Clin Oncol. 2005;23(15):3366-3375.

28. Rades D, Rudat V, Veninga T, Stalpers LJ, Basic H, Karstens JH, Hoskin PJ, et al. A score predicting posttreatment ambulatory status in patients irradiated for metastatic spinal cord compression. Int J Radiat Oncol Biol Phys. 2008;72(3):905-908.

29. Lawton AJ, Lee KA, Cheville AL, Ferrone ML, Rades D, Balboni TA, Abrahm JL. Assessment and Management of Patients With Metastatic Spinal Cord Compression: A Multidisciplinary Review. J Clin Oncol. 2019;37(1):6171.

30. Nieder C, Mannsaker B, Dalhaug A, Pawinski A, Haukland E. The Glasgow prognostic score: Useful information when prescribing palliative radiotherapy. Mol Clin Oncol. 2017;6(6):811-816.

31. van der Linden YM, Steenland E, van Houwelingen HC, Post WJ, Oei B, Marijnen CA, Leer JW, et al. Patients with a favourable prognosis are equally palliated with single and multiple fraction radiotherapy: results on survival in the Dutch Bone Metastasis Study. Radiother Oncol. 2006;78(3):245-253.

32. Butala AA, Lo SS, Jones JA. Advanced radiotherapy for metastatic disease-a major stride or a futile effort? Ann Palliat Med. 2019;8(3):337-351. 